2018-08

\title{
Microplastics in marine sediments near Rothera Research Station, Antarctica
}

\section{Reed, S}

http://hdl.handle.net/10026.1/11865

10.1016/j.marpolbul.2018.05.068

Marine Pollution Bulletin

Elsevier

All content in PEARL is protected by copyright law. Author manuscripts are made available in accordance with publisher policies. Please cite only the published version using the details provided on the item record or document. In the absence of an open licence (e.g. Creative Commons), permissions for further reuse of content should be sought from the publisher or author. 


\section{Disclaimer:}

This is a pre---publication version. Readers are advised to refer to the final published version. https://www.sciencedirect.com/science/article/pii/S0025326X18303977?via\%3Dihub

\section{Microplastics in marine sediments near Rothera Research Station, Antarctica}

Sarah Reed ${ }^{1,2}$, Marlon Clark ${ }^{1,3}$, Richard Thompson ${ }^{3}$ and Kevin A. Hughes ${ }^{1 *}$

${ }^{1}$ British Antarctic Survey, Natural Environment Research Council, High Cross, Madingley Road, Cambridge CB3 OET, UK

${ }^{2}$ Scottish Association for Marine Science, Scottish Marine Institute, Oban, Argyll, PA37 1QA

${ }^{3}$ University of Plymouth, Davy Building, Drake Circus, Plymouth, Devon, PL4 8AA

* corresponding author: E-mail: kehu@bas.ac.uk; Tel: +44 (0)1223221616 


\begin{abstract}
Antarctica and surrounding waters are often considered pristine, but may be subject to local pollution from tourism, fishing and governmental research programme activities. In particular, the quantification of microplastic pollution within the Antarctic Treaty area (south of latitude $60^{\circ} \mathrm{S}$ ) has received little attention. We examined microplastic particle concentrations in sediment samples from 20 locations up to $7 \mathrm{~km}$ from Rothera Research Station. The highest concentrations of microplastic $\left(<5\right.$ particles $\left.10 \mathrm{ml}^{-1}\right)$ were recorded in sediment collected near the station sewage treatment plant outfall. The concentrations were similar to levels recorded in shallow and deep sea marine sediments outside Antarctica. The detected microplastics had characteristics similar to those commonly produced by clothes washing. We recommend further research on microplastics around Antarctic stations to inform policy discussions and the development of appropriate management responses.
\end{abstract}

Keywords: Microplastics; sediment; Antarctic Peninsula; pollution; Protocol on Environmental Protection to the Antarctic Treaty; human impact.

\title{
Highlights
}

- The Antarctica environment is remote and pristine compared to other regions

- Microplastics were detected in marine sediments around Rothera Research Station

- Microplastic levels were comparable with those found in marine sediments worldwide

- A likely source was treated laundry grey water from the station sewage outfall

- Further microplastics research would inform Antarctic policy and management 


\section{Introduction}

Floating macro-debris and microplastics (particles $<5 \mathrm{~mm}$ ) are ubiquitous within all the world's oceans (Spengler and Costa, 2008; Schlining et al., 2013; Bergmann, 2015) including the Southern Ocean and near shore waters around the Antarctic continent (Barnes et al., 2010; Waller et al., 2017). Polar marine ecosystems already face increasing pressures from ocean acidification, climate change impacts, illegal, unreported and unregulated fishing and pollution (Tin et al., 2009; Obbard et al., 2014; Thompson, 2004; DeBoyer et al., 2014). Added to this, microplastics may present significant environmental concerns, as their small size and density may make them accessible for ingestion by a wide range of organisms, potentially leading to physical or toxicological effects (Arthur et al., 2009; Law and Thompson, 2016; Waller et al., 2017). The availability of data on plastic debris distribution in Antarctica and any associated environmental impact is currently limited (see the recent review by Waller et al., 2017). Microplastics have already been found on the subAntarctic island of South Georgia, via ingestion by seals and birds (Barnes, 2005; Barnes et al., 2010), within sediments near the Mario Zucchelli Station, (Northern Victoria Land; Munari et al., 2017), in the surface waters of the Pacific sector of the Southern Ocean (Isobe et al., 2017) and the Ross Sea (Cincinelli et al., 2017). Isobe et al. (2017) suggest that once microplastics are south of the Polar Front within the Southern Ocean, they may become trapped in the Antarctic circumpolar current around Antarctica.

Microplastics may originate from different sources. Larger plastic debris delivered into the marine environment from terrestrial sources (e.g. by being lost or dumped at sea) may be broken down into smaller particles by ultraviolet radiation and physical processes (Gregory and Ryan, 1997; Nerland et al., 2014). Alternatively, microbeads in cosmetic products or microfibers produced following washing of clothing made from synthetic material may be released to the sea in wastewater; for example, up to 728,000 fibres can be released from a $6 \mathrm{~kg}$ washing load of acrylic fabrics (Napper and Thompson, 2016). In Antarctica and the Southern Ocean, the low volume of shipping and lack of a substantial human population compared to the other continents means that 
local sources of microplastics may be few (Waller et al., 2017). Most of the continent's estimated 4,000 transient summer inhabitants live and work within the research stations operated by national Antarctic programmes. Each national programme that operates within the Antarctic Treaty area (the area south of latitude $60^{\circ} \mathrm{S}$ ) is obliged to follow waste disposal practices in accordance with the Protocol on Environmental Protection to the Antarctic Treaty, but treatment standards vary and may depend upon the size, location and sophistication of the research station (Antarctic Treaty Secretariat, 1998a,b; United States, 2006). Grondahl et al. (2009) found that $~ 54 \%$ of the 71 Antarctic Research Stations studied had some form of wastewater treatment, but their effectiveness at removing microplastic from effluent is largely unknown (Waller et al., 2017)

The aim of this study was to access the presence and concentration of microplastic pollution within sediment from intertidal and near shore marine locations in the vicinity of Rothera Research Station, Adelaide Island $\left(67^{\circ} 34^{\prime} 0 \mathrm{~S}, 68^{\circ} 08^{\prime} 0 \mathrm{~W}\right)$, which lies to the west of the Antarctic Peninsula. We also aimed to identify the characteristics of any microplastics to determine their likely source.

\section{Methods}

\subsection{Study Location}

The United Kingdom's Rothera Research Station is a permanently manned station situated on Rothera Point, Adelaide Island, to the west of the Antarctic Peninsula. Rothera Point is a rocky promontory that projects into Marguerite Bay (Figure 1). Around 100 scientists and research support personnel occupy the station during the austral summer (November to April), with this number falling to approximately 20 during the winter months. A biological sewage treatment plant was installed at Rothera Research Station in February 2003 with the plant outfall discharging into the intertidal zone at North Cove (see Figure 1).

\subsection{Sample collection}


Near shore marine sediment samples were collected by diving or box coring between January 2016 and March 2016. Sample areas located near Rothera Point included North Cove, Cheshire Island (c. $200 \mathrm{~m}$ from the station wharf) and South Cove (see Figure 1). While all of these sites were within c. $100 \mathrm{~m}$ of Rothera Point, the distance to the station sewage outfall (either directly or along the coastline) varied between 10 and $2125 \mathrm{~m}$ (see Figure 1). Further sediment samples were collected from locations further way from Rothera Point, i.e. Mackay Point (c. 4 km), Bambay (c. 4.5 km) and Rose Garden (Anchorage Island; c. 7 km) (see Figure 1). Divers used new sterile $500 \mathrm{ml}$ bottles to take arc-shaped samples of the upper $\sim 3 \mathrm{~cm}$ of marine sediment. At each sampling site, three replicate sediment samples were taken. In addition, a site adjacent to the sewage treatment plant outfall in North Cove was sampled using a box corer.

\subsection{Sample processing}

All sample processing was conducted in a contamination-restricted laboratory, where those handling the samples wore $100 \%$ cotton clothing and where hands and nails were washed thoroughly before analysis. Before sampling, all exposed clothing was swabbed with a roller to remove settled fibres. The work surface was cleaned before and after each sample was processed. Checks for contamination during processing were made by exposing a Petri dish containing damp filter paper to account for suspended air contaminants.

Microplastics were extracted from $10 \mathrm{ml}$ sediment sub-samples with a concentrated $\mathrm{NaCl}$ solution $\left(1.2 \mathrm{~kg} \mathrm{NaCl}^{-1}\right)$ and three filtering extractions. To ensure the $\mathrm{NaCl}$ solution was free of plastic fibres it was passed through filter paper until no fibres were detected. The method employed supernatant filtering through a Whatman GF/A $47 \mathrm{~mm}$ glass microfiber filter. Using a stainless steel scoop, $10 \mathrm{ml}$ of each sample was weighed, then added to a glass separating funnel, after which 200 $\mathrm{ml}$ of saturated $\mathrm{NaCl}$ solution was added. The flask was shaken vigorously by hand for 30 seconds, covered with foil, and then left to stand for 5 minutes to allow the sediment to settle out. The salt solution was decanted into a glass filter funnel and care was taken to avoid pouring in any of the 
sediment that had settled out (see Hidalgo-ruz et al., 2012). The sample liquid was poured into the filter apparatus over three filtrations to prevent sediment build up. After all the liquid was removed from the sediment, a further $100 \mathrm{ml}$ of $\mathrm{NaCl}$ solution was added and filtered to produce three additional sub-samples. This was repeated for a third time, resulting in nine sub-sample filter papers for every sediment sample. Therefore, there were 27 filter papers for the three sediment samples collected from each location. All filter papers were examined for microplastic particles using a binocular microscope. A control blank was completed between each sample, where $200 \mathrm{ml}$ of $\mathrm{NaCl}$ solution underwent the same procedure and the filter paper was checked to ensure no microplastics were present. The microplastic detection limit was considered to be fragments down to $0.1 \mathrm{~mm}$ in maximal length.

\subsection{Microplastic material analysis}

Analysis of the composition of the identified microplastics was conducted using a Bruker IFS66 Fourier transform-infrared (FT-IR) spectrometer with a mercury cadmium telluride detector operating in the $600-4000 \mathrm{~cm}^{-1}$ wave number range (see Woodall et al., 2014). A Specac DC-2 Diamond compression cell ( $2 \mathrm{~mm}$ in diameter) was used to allow transmission of the IR beam to the detector. Bruker's OPUS 5.5 spectroscopy software was used during measurement, processing and evaluation of the IR spectra. Spectra were used to determine particles composed of natural material (e.g. cotton, silk, wool) as well as synthetic and semi-synthetic materials (e.g. rayon, acrylic, nylon). Spectra of potential contaminants, such as those from the collection bottles and the FT-IR spectrometer were added to the library in order to eliminate any contamination from the data. No matches with these materials were found in any of the samples.

\section{Results}

\subsection{Microplastic distribution}


Triplicate sediment samples were analysed from 20 locations within the six sample areas (Figure 1 and Supplementary Table S1). The highest concentrations of particles were found in samples obtained from within North Cove close to the sewage treatment plant outfall and to a lesser degree, Cheshire Island. Sediment samples collected from sites greater than $1.6 \mathrm{~km}$ from the outfall had microplastic particle concentrations either at or below the detection limit (i.e. one particle $>0.1 \mathrm{~mm}$ maximal diameter per $10 \mathrm{ml}$ replicate sample) with, for example, no particles detected at Rose Garden c. $7 \mathrm{~km}$ from the station (Supplementary Table 1 and Figure 2). A total of 31 microplastic particles were found within the samples collected in this study.

\subsection{Microplastic material}

The microplastic particles from the sediments were diverse in colour, including white and vibrant reds, green and turquoise; however, $20 \%$ of the particles were black or blue. The microplastic particles were almost all fibres, commonly $2-5 \mathrm{~mm}$ in maximal length and less than $0.1 \mathrm{~mm}$ in diameter. One sample from North Cove contained one microplastic particle that was spherical in shape and may have originated from the degradation of a larger plastic object. Consequently, the plastic particles detected may have originated from a number of materials, including, for example, synthetic fibres with a long-thin form that may be indicative of textiles from clothing, cleansing wipes and hygiene products. Analysis of the composition of the particles showed that rayon, a semi-synthetic fibre, was most common (comprised $42 \%$ of all the particles examined) and found only in samples collected from North Cove and Cheshire Island, the two locations closest to the research station outfall.

\section{Discussion}

This study has revealed the level of microplastic pollution in near shore marine sediments collected in the vicinity of Rothera Research Station, Adelaide Island. The highest particle abundances where recorded in North Cove, and the sewage treatment plant outflow that empties into the cove is a 
likely source of these microplastics. Supporting this hypothesis, the shape and composition of the detected fibres were indicative of those generated during clothes washing (Andrady et al., 2011; Napper and Thompson, 2016). Rayon fibres were most common and were only detected within 1.6 $\mathrm{km}$ of the outfall, suggesting that the released station grey water may have been the source. The microplastics found at the Cheshire Island sample site (located $1.6 \mathrm{~km}$ along the cost from the outfall) may have originated from the sewage outfall, or possibly from the Biscoe Wharf, located $200 \mathrm{~m}$ to the east. In general, microplastic concentrations in sediments were of a similar order of magnitude to concentrations found globally in deep ocean, shallow water marine and beach sediments (Brown et al., 2011; Woodall et al., 2014).

Waller et al. (2017) recently reviewed the topic of microplastic contaminations within the Antarctic marine system and estimated that levels of microplastic pollution released into the region from ships and scientific research stations were most likely negligible on the scale of the Southern Ocean. Their calculations were based upon the assumption that all released particles were distributed homogeneously within the Southern Ocean, but did suggest that microplastic pollution had the potential to be more concentrated at a local scale around point sources. In our study, microplastics fibres detected in North Cove are likely to have originated from the outfall; however, across all the sample locations, pollution from other sources (such as plastics originating from outside the local area or Antarctica) cannot be discounted. This may be true particularly for microplastic particles (as opposed to microplastic fibres) as their release from local sewage outfalls may be less likely.

Effluent has been released from Rothera Research Station for over 40 years, and microbial tracers have demonstrated the presence of currents in North Cove (Hughes, 2003). The low concentrations of microplastics detected in the vicinity of the outfall suggest that these currents may be effective in the wider dispersal of microplastics away from the station. In a similar study, Munari et al. (2017) recorded microplastics in all samples collected up to $10 \mathrm{~km}$ from Mario Zucchelli Station, Terra Nova Bay, Ross Sea, Antarctica. They recorded 1661 items of microplastic 
(totalling $3.14 \mathrm{~g}$ ) within 31 sediment samples, with concentrations decreasing with increasing distance from the base. Waller et al. (2017) found between 16 and 766 synthetic particles $\mathrm{m}^{-2}$ in sediments and macroalgal material collected at depths of 6 to $60 \mathrm{~m}$ from Mackellar Inlet, Admiralty Bay, South Shetland Islands, close to the Peruvian Machu Picchu research station. No clear pattern of abundance or distribution was observed; however, potential outputs from other research stations in the vicinity of Admiralty Bay may have complicated the pattern detected. In a study of plastics in seawater samples from the Ross Sea, including near Mario Zucchelli Station, Cincinelli et al. (2017) found the highest concentration of pelagic microplastics in the sample collected close to the effluent originating from the Mario Zucchelli Station. These studies suggest that Antarctic research stations may act as point sources of release of microplastic particles, although the impacts on local wildlife remain largely unknown (Lusher et al., 2013; Gall and Thompson, 2015).

The Antarctic Treaty System is the agreed mechanism for governance within the Antarctic Treaty area. The wider issue of microplastic pollution has only emerged in the time after the Protocol on Environmental Protection to the Antarctic Treaty was agreed in 1991, and consequently the Protocol does not address the issue of microplastic pollution directly. Annex III 'Waste Disposal and Waste Management' to the Protocol states that sewage and domestic liquid wastes may be discharged directly into the sea, as long as (i) conditions exist for initial dilution and rapid dispersal and (ii) large quantities of wastes be treated at least by maceration. The Annex also states that all plastic shall be removed from Antarctica, with the only exception being those plastics that can be incinerated without producing harmful emissions. Antarctic Treaty Consultative Parties, and in particular their Committee on Environmental Protection, have yet to undertake comprehensive discussions on the issue of microplastics. However, given the paucity of studies on microplastic pollution within Antarctica, and those near research stations and popular tourist visitor sites in particular, we would encourage further research on microplastic pollution levels and likely impacts to inform policy discussion and recommendations on possible practical responses. 


\section{Acknowledgements}

This paper contributes to the British Antarctic Survey (BAS) Polar Science for Planet Earth (PSPE) Biodiversity, Evolution and Adaptation programme and the Environment Office Long Term Monitoring and Survey (EO-LTMS) project. This work was supported by the British Antarctic Survey Environmental Office and The University of Plymouth. The Rothera Research Station Marine Team is thanked for assistance with sample collection and Laura Gerrish of the BAS Mapping and Geographic Information Centre (MAGIC) for map preparation. We acknowledge the useful comments of two anonymous reviews in the improvement of this manuscript. 


\section{References}

Arthur, C., Baker, J., Bamford, H., 2009. Proceedings of the international research workshop on the occurrence, effects and fate of microplastic marine debris, 9-11 September 2008, NOAA Technical, Memorandum NOS-OR\&R30.

Andrady, A. L., 2011. Microplastics in the Marine Environment. Marine Pollution Bulletin 62, 1596-1605.

Antarctic Treaty Secretariat, 1998a. Protocol on Environmental Protection to the Antarctic Treaty. Accessed at http://www.ats.aq on 22 May 2017.

Antarctic Treaty Secretariat, 1998b. Annex III to the Protocol on Environmental Protection to the Antarctic Treaty. Waste disposal and waste management. Accessed at http://www.ats.aq on 22 May 2017.

Barnes, D. K. A., 2005. Remote islands reveal rapid rise of Southern Hemisphere sea debris. The Scientific World Journal 5, 915-921.

Barnes, D. K. A, Walters, A., Gonçalves, L., 2010. Macroplastics at sea around Antarctica. Marine Environmental Research 70, 250-252.

Bergmann, M., 2015. Marine anthropogenic litter. Springer Cham Heidelberg.

Browne, M.A., Crump, P., Niven, S.J., Teuten, E., Tonkin, A., Galloway, T., Thompson, R., 2011. Accumulation of microplastic on shorelines worldwide: sources and sinks. Environmental Science and Technology 45, 9175-9179. 
Cincinelli, A., Scopetani, C., Chelazzi, D., Lombardini, E., Martenllini, T., Katsoyiannis, A., Fossil, M. C., Corsolini, S., 2017. Microplastic in the surface waters of the Ross Sea (Antarctica): occurance, distribution and characterisation by FTIR. Chemosphere 175, 391-400

De Broyer C., Koubbi P., Griffiths H.J., Raymond B., Udekem d'Acoz C. d', Van de Putte A.P., Danis B., David B., Grant S., Gutt J., Held C., Hosie G., Huettmann F., Post A., Ropert-Coudert Y. (eds.), 2014. Biogeographic atlas of the Southern Ocean. Scientific Committee on Antarctic Research, Cambridge, XII + 498 .

Gall, S.C., Thompson, R.C., 2015. The impact of debris on marine life. Marine Pollution Bulletin $92,170-179$.

Gröndahl, F., Sidenmark, J., Thomsen, A., 2009. Survey of wastewater disposal practices at Antarctic research stations. Polar Research 28, 298-306.

Gregory, M.R., Ryan, P.G., 1997. Pelagic plastics and other seaborne persistent synthetic debris: a review of Southern Hemisphere perspectives. In: Coe, J.M., Rogers, D.B. (Eds.), Marine debris, sources, impacts, solutions. Springer-Verlag, New York, pp 49-66.

Hidalgo-ruz, V., Gutow, L., Thompson, R. C., Thiel, M., 2012. Microplastics in the marine environment: A review of the methods used for identification and quantification. Environmental Science and Technology 46, 3060-3075. 
Hughes, K. A., 2003. Influence of seasonal environmental variables on the distribution of presumptive fecal coliforms around an Antarctic research station. Applied and Environmental Microbiology 69, 4884-4891.

Isobe, A., Uchiyama-Matsumoto, K., Uchida, K., Tokai, T., 2017. Microplastics in the Southern Ocean. Marine Pollution Bulletin 114, 623-626.

Law. K.L, Thompson, R. C., 2016. Microplastics in the sea: Concern is rising about widespread contamination of the marine environment by microplastics. Science 345, 61-93.

Lusher, A.L., McHugh, M., Thompson, R.C., 2013. Occurrence of microplastics in the gastrointestinal tract of pelagic and demersal fish from the English Channel. Marine Pollution Bulletin 67, 569 94-99.

Munari, C., Infantini, V., Scoponi, M., Rastelli, E., Corinaldesi, C., Mistri, M., 2017. Microplastics in the sediments of Terra Nova Bay (Ross Sea, Antarctica). Marine Pollution Bulletin 122, 161165.

Napper, I. E, Thompson, R., C., 2016. Release of synthetic microplastic fibres from domestic washing machines: Effects of fabric type and washing conditions. Marine Pollution Bulletin 112, $39-45$.

Nerland, I. L., Halsband, C., Allan, I., Thomas, K. V., 2014. Microplastics in marine environments: occurrence, distribution and effects. (No. 6754-2014), Oslo. 
Spengler, A., Costa, M.F., 2008. Methods applied in studies of benthic marine debris. Marine Pollution Bulletin 56, 226-30.

Tin. T., Fleming. Z. L., Hughes. K. A, Ainley, D. G, Convey. P., 2009. Impacts of local human activities on the Antarctic environment. Antarctic Science 21, 3-33.

Schlining, K., von Thun, S., Kuhnz, L., Schlining, B., Lundsten, L., Jacobsen Stout, N., Chaney, L., Connor, J., 2013. Debris in the deep: Using a 22-year video annotation database to survey marine litter in Monterey Canyon, Central California, USA. Deep-Sea Research 46, 12-16.

Obbard, R. W., Sadri, S., Wong, Y. Q., Khitun, A. A., Baker, I., Thompson, R. C., 2014. Global warming releases microplastic legacy frozen in Arctic Sea ice. Earth's Future 2, 315-320.

Thompson, R., 2004. Lost at sea; where is all the plastic? Science 128, 838-838.

United States, 2006. Wastewater treatment in Antarctica: challenges and process improvements. Information Paper 60. Antarctic Treaty Consultative Meeting XXIX, 12 - 23 June 2006, Edinburgh, United Kingdom.

Waller, C. L., Griffiths, H. J., Waluda, C.M., Thorpe, S. E., Loaizac, I., Morenoc, B., Pacherresc, C. O., Hughes, K. A. 2017. Microplastics in the Antarctic marine system: An emerging area of research. Science of the Total Environment 598, 220 - 227.

Woodall, L.C., Sanchez-vidal, A., Paterson, G.L.J., Coppock, R., Sleight, V., Calafat, A., Rogers, A.D., Narayanaswamy, B.E., Thompson, R.C., 2014. The deep sea is a major sink for microplastic debris. Royal Society Open Science 1, 1403-1472. 


\section{Figures}

Figure 1. Map showing the locations of all samples sites (for more details see Supplementary Table

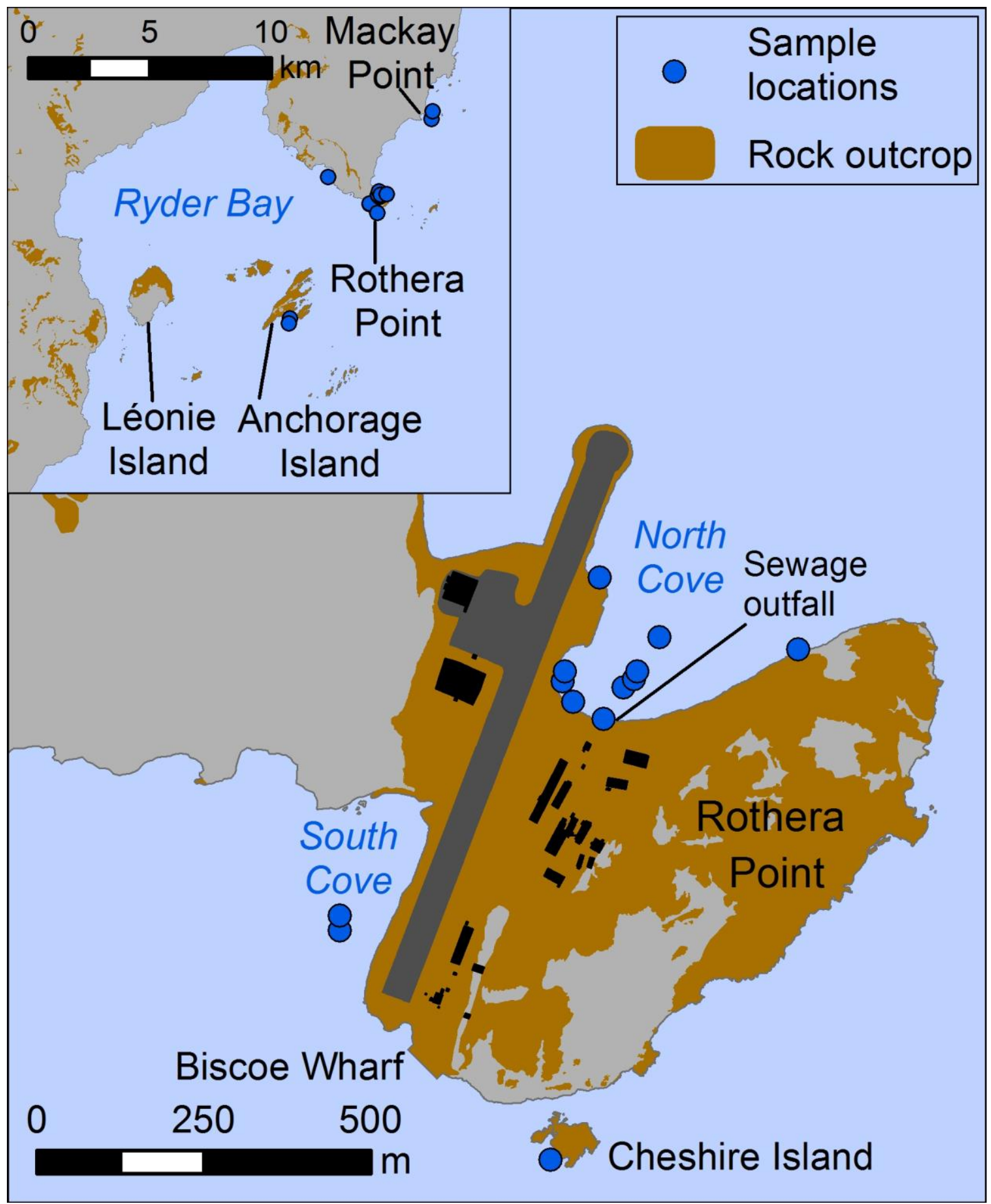


Figure 2. Concentration of microplastic particles detected in sediment samples collected in the vicinity of Rothera Research Station, Antarctica. Distances from the sewage treatment outfall in North Cove are shown; distances are either 'straight line' (i.e. North Cove, Mackay Point) or measured along the shoreline (i.e. Cheshire Island, South Cove, Bambay and Rose Garden). See Supplementary Table 1 for full details of the particles and fibres found in samples

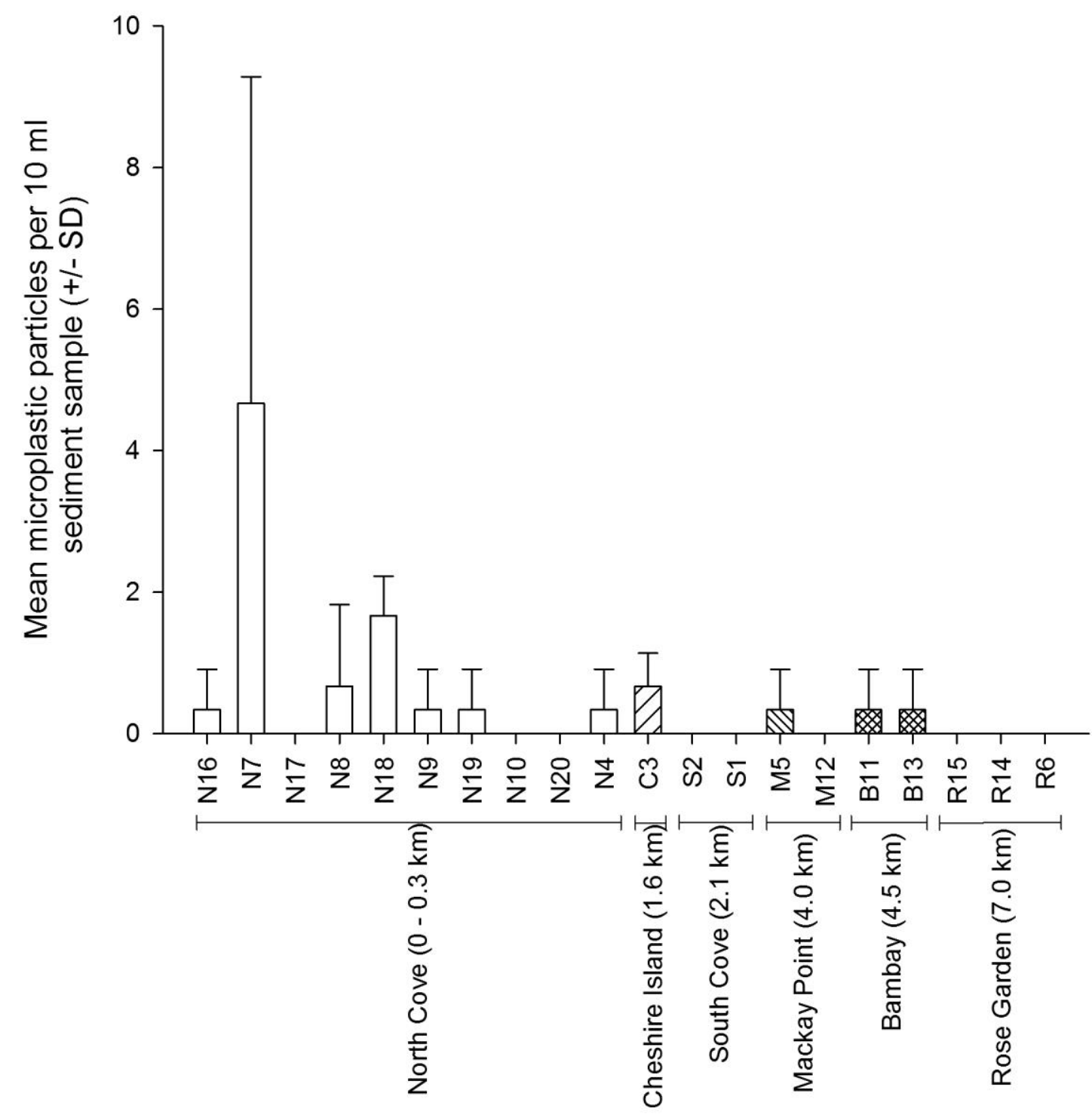

Sample number, location and approximate distance from station outfall 
